\title{
La investigación en tiempos de contingencia del Covid 19
}

Pocas veces el hombre se había enfrentado a una prueba de tan semejantes proporciones, como la que se presenta con el Covid 19, en cuestión de semanas la sociedad ha sido testigo de una transformación en su cotidianidad, lo que significa una manera constante y diferente en la forma de repensar las actividades diarias.

Es bien sabido por muchos que no es la única pandemia por la que ha pasado la humanidad, se tiene conocimiento más o menos desde el año 1200 a. C. cuando al parecer se dieron los primeros registros de oleadas virulentas y de pestes en la antigua Babilonia.

En cuanto a las hipótesis del origen del Covid 19, actualmente abundan y rondan en el ámbito científico y popular, sin embargo, hasta ahora no se ha logrado establecer con absoluta certeza cómo se desató el mencionado virus, algunos científicos coinciden que fue en forma natural, lo cierto es que el ser humano está enfrentando una compleja situación en todos los frentes.

Así pues, el sector investigativo no escapa a estas circunstancias, los retos que plantea, cuidados extremos, la adaptación a la virtualidad, caídas del Internet, más tiempo en el computador, falta de interacción presencial, largas jornadas laborales y todo lo que conlleva la adaptación a lo que algunos llaman nueva normalidad, trae consigo, que el momento actual tenga sus altibajos, que a veces parecieran no tener salida.
No obstante y teniendo en cuenta algunos cambios que se han puesto en marcha como los que tienen que ver con el autocuidado y el de la familia, debemos ver también oportunidades que nos plantea la crisis actual, como por ejemplo el fortalecimiento de herramientas tecnológicas, de búsqueda y verificación de información, uso de nuevas plataformas, capacitaciones virtuales, nuevas formas para comunicarnos y de transmitir información relevante rápidamente, son algunas destrezas que se van implementando poco a poco.

De ahí entonces, que este es un inmenso agradecimiento y un llamado a la unidad, la esperanza y a no perder el norte para continuar en la búsqueda del mejoramiento de las condiciones económicas, sociales, culturales, etc. a quienes por medio de valiosos aportes a la ciencia desde todas las áreas del conocimiento y que surgen del esfuerzo de autores, investigadores, revisores, docentes, estudiantes, editores, colaboradores y en general de todos quienes apoyan la academia y el indagar constante, isigan adelante! en franca lid con los métodos que la ciencia ha puesto a disposición, logrando admirables resultados y avances en la investigación científica y académica.

Para concluir invito entonces a todos los colegas a mantener la antorcha de la ciencia y la sabiduría encendidas, enfocados en la búsqueda de la verdad y el conocimiento, de la mano del 
postulado de Sócrates "solo sé que nada sé", frase que sintetiza la humildad, la tenacidad y la perseverancia de los hombres de ciencia.

\section{Esp. Julio César Uribe Vanegas \\ Asistente de Editorial juribe@lasallista.edu.co}

\section{Referencias}

Fernández, J. (2020) COVID-19: Cientificos confirman que su origen es natural https:// biotechmagazineandnews.com/covid-19cientificos-confirman-que-su-origen-esnatural/

Mouritz, A. (1943). A Brief World History of Leprosy Honolulu, Hawaii, U.S. America https://collections.nlm.nih.gov/ bookviewer?PID=nlm:nlmuid-101283076bk\#page/3/mode/1up 